\title{
Sugar in disguise or healthy indulgence: A cross-cultural comparision of the perceptions of dietary vice/virtue bundles
}

\author{
Napatsorn JIRAPORN \\ State University of New York at Oswego, New York, United States
}

Alisara Rungnontarat CHARINSARN

Thammasat University, Bangkok, Thailand

Alisara@tbs.tu.ac.th

Michael SHERIDAN

State University of New York at New Paltz, New York, United States

\begin{abstract}
Consumers often choose virtue food to attain health goals and vice food to achieve indulgence goals. However, food and beverage companies have begun to nullify the vice and virtue categories by bundling vice and virtue ingredients into a single item (e.g. Yogurt with Oreo topping). This research contrasts how consumers from Asian and Western cultures evaluate such vice/virtue food bundles. Building on the perceptual processes and regulatory focus literatures, two cross-cultural experiments using participants in Thailand and the U.S. shows that Westerners prefer virtue-heavy bundles to vice-heavy bundles while Asians show similar preference across both types of bundle. Process measures revealed that Asians perceive greater fit between vice and virtue components in the bundles than Westerners and this perceived fit mediates the effect of culture on their food choice. Study 2 reveals the boundary condition. Specifically, when regulatory focus was manipulated, the effect of culture is no longer significant. The findings provide managerial implications for food and beverage companies as well as contributions to consumer behavior literature.
\end{abstract}

Keywords: food consumption, guilt, hedonic consumption, goal conflict, product bundles.

Please cite the article as follows: Jiraporn, N., Charinsarn, A.R. and Sheridan, M. (2016), "Sugar in disguise or healthy indulgence: A cross-cultural comparision of the perceptions of dietary vice/virtue bundles", Management \& Marketing. Challenges for the Knowledge Society, Vol. 11, No. 2, pp. 410-430, DOI: 10.1515/mmcks-2016-0006.

\section{Introduction}

Many consumers assume that food cannot be tasty and nutritious (Raghunathan et al., 2006) and thus tend to employ a heuristic that classifies virtuous foods as "healthy but not tasty" and vice foods as "unhealthy but tasty" (Chernev and Gal, 2010, Rozin et al., 1996, Wertenbroch, 1998). This trend can be observed even in the most health conscious consumers, which shows that they consider such characteristics during real food purchases (Istudor and Pelau, 2011). As such, consumers envision dietary choices as a tradeoff; consume virtuous foods to attain health goals, or consume vice foods to indulge. However, food and beverage companies have begun to nullify this perceived dichotomy by bundling vice and virtue ingredients (for example, Oreo cookies in Yocrunch Yogurt), which addresses the consumer's desire to gain health benefits, but without the cost of adopting extreme measures to do so (Kristensen et al., 2013). Although such products have become more common, few researchers have examined 
how consumers evaluate a combination of vice and virtue within a single food product (Liu et al., 2015). Moreover, little is known how individual characteristics impact the evaluation of these vice-virtue bundles.

The current research seeks to understand the role of one individual characteristic, culture, in consumers' perceptions of dietary vice-virtue bundles that contain varying ratios of vice and virtue ingredients. We do this by conducting two related studies: In the first, we draw from the holistic thinking literature (summarized in Nisbett and Miyamoto, 2005) which identifies the different heuristics Asians and Westerners deploy when making sense of objects in the environment. Asians display a propensity towards holistic thinking and thus are more likely to consider the context in which the items appear. In contrast, Westerners tend to engage in a more analytic thinking style and are prone to focus more upon the functionality of an item rather than the context in which it appears. Therefore, relative to Asians, Westerners may perceive greater conflict between vice and virtue components since their purposes seem contradictory. Results of our study indicate that differences between the cultures exist, as Westerners showed stronger preference for vice-virtue bundles with a higher virtue ratio (vs. higher vice ratio), while Asian consumers exhibited no preference between the bundles.

In the second study, we sought to determine the existence of boundary conditions of the cultural differences observed in Study 1. To do so, we primed the subjects' regulatory focus and found that the regulatory condition often negates the influence of culture upon the perception of vice-virtue bundles. The results revealed that relative to prevention-focused participants, promotion-focused participants were more likely to choose both types of bundles. These results led to the conclusion that Western and Asian consumers perceived vice-virtue bundles differently, with Asian participants' holistic thinking contributing to more positive evaluations of the bundles. Moreover, we demonstrate that an activation of an individual's regulatory focus (Higgins, 1998) can override these cultural differences. These findings will assist businesses to better understand consumers, particularly when they do not simply average the characteristics of the bundle (Chandon and Wansink, 2007, Chernev and Gal, 2010, Schuldt et al., 2012), but engage in a more complex calculation that assesses both their taste and health goals.

The remainder of the article is structured as follows. We begin by reviewing related literature to discuss our hypotheses. Then, we present our method and results of the two analyses, followed by a general discussion of our findings. The article concludes with our theoretical contributions, managerial implications and limitations, as well as possible extensions of our research.

\section{Theoretical background}

\section{Categorizing vice and virtue}

Prior research suggests that consumers often rely upon a typology that classifies choices as either bad (vice) or good (virtue) (Chernev and Gal, 2010). Vices provide immediate gratification, but fail to offer long-term benefits, such as the achievement of health goals. Conversely, virtues offer long-term benefits, but do not provide immediate gratification. For example, indulgent foods such as ice cream are often considered vices as they produce immediate pleasure in terms of taste, yet these foods rarely provide long-term health benefits. In contrast, vegetables, which are considered healthy, but not necessarily tasty, are classified as virtues. However, these dichotomies become muddled when vice and virtue appear simultaneously but in separate components, such 
as burger served with salad (Chernev and Gal, 2010, Read et al., 1999, Rozin et al., 1996, Wertenbroch, 1998).

Food manufacturers are well ahead of the literature regarding vice-virtue bundles and have already introduced products that typify this strategy. For example, both Pepsi and Coca Cola have offered a vitamins-fortified cola beverage with the hope that consumers will perceive it as a healthy soda and will not feel the need to compromise between the taste and health benefits. Additionally, chocolates have been fortified with added vitamins, as many other vice options widely available in supermarkets. Indeed, one may argue that the rapidly-growing subproduct category of organic junk food is the archetype of the vice-virtue bundle approach.

Existing research regarding vice-virtue bundles state that consumers average the characteristics of each component and consume more calories in the erroneous belief that they are advancing health goals (Chandon and Wansink, 2007, Chernev and Gal, 2010, Schuldt et al., 2012). Yet, much of the previous research in this stream has failed to consider the contexts in which vice and virtue components are bundled together into the same item (e.g. calcium-fortified chocolate and yogurt with M\&M topping). In response, scholars have recently struck a more granular perspective on this marriage of vice and virtue by exploring the changes in the decision making process when the vice and virtue ratios are manipulated within a single package. In these scenarios, researchers have shown that participants tend to calculate their cost/benefit analysis differently (Liu et al., 2015, Milkman et al., 2013).

A brief example illustrates this point well. When researchers presented activities on opposite ends of the spectrum separately, people expectedly delayed virtuous activities but immediately engaged in indulgent behavior (Read et al., 1999). However, when a want task (vice) was embedded within a should activity (virtue), the unpleasantness of the virtuous activity decreased. This bundling led to a related increase in willpower and a willingness to engage in a virtuous activity sooner. Moreover, when participants faced the opposite scenario (a should task containing a small amount of want activity), they reported less guilt when indulging (Milkman et al., 2013). Extending Milkman's work into the context of food, Liu and associates (2015) analyzed the perception of dietary bundles that contained varying proportions of vice. They found that participants preferred small amounts of vice with their virtue, but also perceived the bundles with a small amount of vice to be equally as tasty as bundles with larger proportions (Liu et al., 2015).

These studies show that when vice and virtue components appear simultaneously, our perception shift in ways that are substantially different than our perception of separate components. This suggests that the combination of vice and virtue in a single package may negate the traditional dichotomous perspective of food choice in favor of a continuum that considers increments of vice and virtue (Raghunathan et al., 2006). Moreover, further analysis of these combinations may better serve the desires of consumers that do not wish to sacrifice their health goals for periodic indulgences.

Vice-virtue bundles represent a relatively new topic of inquiry in consumer behaviour and, despite the increased presence of these products in the market, many questions regarding consumers' perceptions remain. For example, little is known regarding the impact of culture on the perception of vice-virtue bundles. Prior research (Reid et al., 2001) comparing consumers in France, Australia, Britain, Denmark, and Singapore reveals that both health and taste of food are simultaneously influential to their food choices. Hence, consumers in different cultures are facing a similar trade-off 
decisions between vice and virtue options. Furthering our knowledge regarding culture may assist marketers to better navigate the increasingly global retail food industry. Therefore, our study aims to shed light on the influence of culture by extending Liu and her associates' (2015). study to determine if Asian and Western consumers exhibit different preferences and perceptions of nutrition and taste when assessing dietary vice-virtue bundles.

\section{Cultural differences in the perceptions of dietary vice-virtue bundles}

Cultural differences in styles of thinking may affect how individuals perceive vice-virtue bundles. Previous research has determined that Westerns tend to engage in an analytical thinking style, while Asians are likely to employ holistic thinking (Abel and Hsu, 1949, Choi et al., 2007, Chua et al., 2005, Kitayama et al., 2003, Masuda and Nisbett, 2000, Nisbett and Miyamoto, 2005, Nisbett et al., 2001). Nisbett and associates (2001) defined analytic thinking as a tendency to detach the object from its context and to focus on attributes of the object in order to assign it to a category. Holistic thinking, on the other hand, is the tendency to perceive the relationships between a focal object and the context as a whole.

For example, when China-born Chinese participants were presented with a Rorschach test, they tended to perceive the blots as a whole pattern; whereas Americanborn Chinese participants more frequently focused on the details of the image (Abel and $\mathrm{Hsu}, 1949)$. Chua later confirmed these earlier findings by demonstrating that Westerns identified focal objects sooner and remained on the object longer than the Chinese subjects (Chua et al., 2005). When these findings were applied to consumer behavior, Monga and John (2007) discovered that the Asian participants' propensity for holistic thinking increased the likelihood they would perceive a brand extension to fit better than their Western counterparts. Moreover, the researchers uncovered a positive correlation between perceived fit and a favorable perception of the brand in this group.

Since culture has been shown to influence the categorization process, such as when assessing food choices (Nisbett and Miyamoto, 2005, McCarty et al., 2007), we expect a similar dynamic to exist in an individual's perception of food items. We expect Western consumers, who are more likely to engage in analytical thought processes, to focus on individual attributes of the food to facilitate categorization (Masuda and Nisbett, 2000, Chiu, 1972). When a food choice contains both vice and virtue attributes, however, the categorization cannot be done as easily, so analytic thinkers may perceive greater conflict within the bundle than holistic thinkers. For example, Western consumers may consider a bundle containing yogurt and Oreos as an incongruent dish, and exhibit less of a fit between its components, since the yogurt and Oreos do not occupy the same position along the taste/health continuum. Moreover, Western diets tend to be less healthy (Zhou et al., 2003) which may cause a heightened sensitivity to the functionality of ingredients and further magnify the incongruence of the vice-virtue bundle in Western consumers.

On the other hand, given the propensity of Asians to search for "thematic interdependence" among disparate objects (Chiu, 1972), we would expect that when Asian consumers are presented with a vice-virtue bundle, they would identify relationships that extend beyond the composition of the individual ingredients within the dish (Choi et al., 2007) and judge the bundle within the context of their overall diet. For example, when presented with the aforementioned cup of yogurt with Oreo topping, the holistic thinker may consider the dish to fall within the snack category, and thus identify a greater fit when compared to more analytical thinkers. 
Hence, we propose that when evaluating dietary vice-virtue bundles, consumers from Western cultures will perceive a greater degree of conflict between vice and virtue components than consumers from Asian cultures. In other words:

H1: Participants from Asian cultures will consider the vice-virtue bundles

to have a greater fit of components than participants from Western cultures.

Moreover, because Western consumers tend to focus more on the individual components of a bundle, we would expect they may consider vice-virtue bundles with a higher ratio of virtue ingredients to be healthier than bundles with higher ratios of vice. In other words:

H2a: Participants from Western cultures will evaluate the virtue-heavy bundles as healthier than the vice-heavy bundles.

Westerner's propensity to focus on individual ingredients within a bundle may also reveal preferences regarding a possible perceived health/taste dichotomy.

H2b: Participants from Western cultures will evaluate the virtue-heavy bundles as less tasty than the vice-heavy bundles.

Asian consumers, on the other hand, tend towards holistic thought processes and we thus expect these consumers to not distinguish the dishes based on the ratios of the vice-virtue components. Therefore, we expected to observe little difference in the perception of the taste and nutrition value of the different bundle types.

$\mathrm{H} 2 \mathrm{c}$ : The perceptions regarding healthiness of food by the participants from

Asian cultures will not be significantly different between the bundle types.

H2d: Similarly, the perceptions regarding tastiness of food by the

participants from Asian cultures will not be significantly different between

the bundle types.

Liu, et al. (2015) demonstrated that American consumers prefer small amounts of vice to accompany their virtuous ingredients and that bundles with high levels of vice were perceived to be equally as tasty as bundles featuring small amounts of vice. Thus:

H3a: Participants from Western cultures will prefer the virtue-heavy bundles rather than the vice-heavy bundles.

Moreover, according to the analytic/holistic thought process typology, holistic thinkers will focus less on the individual components of a bundle. Therefore:

H3b: Participants from Asian cultures will exhibit no preference between the virtue-heavy bundles and vice-heavy bundles.

\section{Regulatory focus in food choices}

Regulatory focus theory contends that individuals employ one of two regulatory preferences when evaluating choices. The first, a promotion focus, emphasizes the "advancement, growth, and accomplishment" of an individual (Higgins, 1997, p. 1282). Whereas the second, the prevention orientation, is geared towards the avoidance of negative consequences and a preference for the safe or responsible choice. Much of the previous work regarding regulatory focus and food choice incorporates regulatory fit theory (Higgins, 2005) in order to assess the degree of congruence between motivational orientation (promotion vs. prevention) and the efforts to achieve one's goals. For example, individuals demonstrating a prevention focus tend to use food to decrease the stress of a negative emotion (Pfattheicher and Sassenrath, 2014) and prefer convenient, stress-reducing and familiar foods (Pula et al., 2014).

However, a number of questions remain regarding the role of regulatory focus on food choice. When Leikas et al. (2006) presented participants with food risks, 
prevention-focused individuals considered risks to be more likely, yet the researchers were unable to develop a similar correlation with promotion-focused individuals. Similarly, Van Kleef and her associates (2005) were unsuccessful in their attempt to establish a link between regulatory focus and the evaluation of a functional food.

Despite the inconsistent results regarding regulatory focus and food choice, researchers have been able to generate promising results in other aspects related to the theory. For example, studies have shown the ability to prime individuals momentarily to adopt a specific orientation (Cesario et al., 2004). Also, Florack et al. (2013) manipulated individual's regulatory orientation to show that individuals in the prevention focus were more likely to approximate social models of appropriate behavior, while others have linked the prevention condition with an increase in the perception of risk likelihood (Leikas et al., 2006).

Manipulating participants' regulatory focus has also been shown to negate the influences of culture. Zhang and Mittal (2007) found that participants in the promotion prime emphasized positive aspects of a choice regardless of their cultural background. Thus, we expect the regulatory focus manipulation will temporarily alter the participants' orientation and override cultural propensities.

H4: Regulatory focus manipulation will temporarily nullify the effects of culture upon the participants' thinking patterns.

Zhu and Meyers-Levy (2007) suggest that promotion-focused individuals tend to engage in relational elaboration which involves integration of themes among dissimilar pieces of information. In contrast, prevention-focused individuals often engage in itemspecific elaboration, which involves encoding precise, concrete associations to each individual item in isolation of others (Hunt and Einstein, 1981). Similarly, Liberman et al. (1999) reported that the participants in the prevention focus tended to process information in a more concrete and detailed level due to their emphasis on safety and responsibilities. Thus, the presence of conflicting components will be seen by the prevention-focused individuals as incongruent with the overall "goal" of the bundle, and thus judge both bundle types to be ill-fitting. In other words,

H5: Participants in promotion-focused condition will perceive greater fit between the vice and virtue components in the bundles than participants in preventionfocused condition.

Next, individuals exhibiting a promotion-focus tend to be drawn towards gains and aspirations (Higgins, 1997, Higgins, 2005, Scholer and Higgins, 2012). When evaluating choices, they were more likely to choose ideal-related or luxury attributes, such as plush seats in a car, over ought-related, or safety, attributes such as antilock brakes (Safer and Higgins, 2001). Thus, it appears that they are less sensitive to negative outcomes and ought-related benefits such as health and safety (Sengupta and Zhou, 2007). In their decision making, promotion-focused individuals tend avoid the error of omission (e.g. foregoing a good opportunity) while prevention-focused individuals are more concerned on the error of commission (e.g. making a poor decision). Alternatively, prevention-focused individuals forgo alternatives to limit the chance of making mistakes (Higgins, 2002, Crowe and Higgins, 1997). Specifically in the domain of food, promotion-focused consumers were found to experience greater desire for food temptation such as cheesecake (Dholakia et al., 2006) than prevention-focused consumers. Thus, we propose that promotion-focused consumers are more likely to be receptive to the allure of vices when evaluating vice-virtue bundles. However, in our study, both types of vice-virtue bundles contain a vice component and each bundle presents an opportunity to experience pleasure with less guilt of consumption. 
Therefore, we propose that promotion-focused consumers, driven by the fear of missing out pleasure and their desire for temptation, would show stronger preference for both types of vice-virtue bundles than prevention-focused consumers who are more conservative in decision making. In other words,

H6: Participants in the promotion condition will exhibit stronger preferences than participants in the prevention condition for both types of bundles.

\section{Methodology}

First, two pretests were conducted to identify food components classified as vice and virtue and develop the vice/virtue bundles as stimuli for the main experiments. Then, two experiments were conducted to test our hypotheses. The first experiment shows the differences between Asian and Western cultures in their evaluation of vice/virtue bundles. The second experiment examines the role of regulatory focus. Data collection was carried out between March 2014 to June 2015.

\section{Pretest I}

To construct our dietary vice-virtue bundles, we first identified components that fell on each end of the health/taste spectrum. We conducted a pretest in which we presented twenty-two Thai and twenty-six American undergraduate students with a list of food categories and ingredients. They were then asked to report their perception of each on four dimensions: tastiness, healthiness, immediate pleasure, and long-term benefits gained from consuming the food. All measures were on a 7-point scale, consistent with the definition of vice and virtue in prior research $7=$ strongly agree that the food is very tasty, healthy, gives me immediate pleasure, and gives me long-term benefits) (Mishra and Mishra, 2011, Read et al., 1999). Then, we classified food categories and ingredients that scored high (low) on healthiness and long-term benefits but low (high) on tastiness, and immediate pleasure as falling into the virtue (vice) category. From this typology, we constructed five vice-heavy food bundles and five virtue-heavy food bundles. For example, according to the pretest, yogurt provides long term health benefits, but not be seen as especially tasty, and therefore participants scored this item high on the virtue scale. M\&M's, on the other hand, was perceived to taste good, but provide few long term health benefits, scoring high on the vice scale. The combination "yogurt with M\&M topping" became a virtue-heavy bundle.

\section{Pretest II}

Once we created the vice-virtue bundles, we ran a second pretest to evaluate the vice and virtue ratios in each of the vice-virtue bundles created from the first pretest. A different pool of respondents ( $n=37$ Thais and 42 Americans) was used in this pretest. Each participants evaluated the perceived virtue score on a rating scale ranging from 0 = vice (very tasty, but not healthy) and 100 = virtue (very healthy, but not tasty). Respondents were instructed that 50 indicated that the option has an equal proportion of vice and virtue components. The result shows an average virtue score for the highvice-ratio options is 32.57 whereas that of high-virtue-ratio options is 71.96 . A pairwise $t$ test shows that the difference in these mean scores is statistically significant $(t(36)=$ $13.75, p<.01$ for Thai and $t(41)=18.62, p<.01$ American respondents). The Cronbach Alphas show acceptable internal consistency within each type of food options $(\infty=.68$ and .61 respectively). The results from both pretests allowed us to create five food options that feature a high vice ratio and five food options with a high virtue ratio. A full 
list of the ten food bundles along with the average perceived virtue percentage are in Table 1.

Table 1: Food options used in the main experiments

Bundles with a High Virtue Ratio

Perceived Virtue Score $(100=$ Virtue $)$

1. Stir-Fried Vegetable with Deep-Fried Pork

73.32

2. Bacon Salad

74.22

3. Chocolate-Dipped Strawberries

74.89

4. Yogurt with M\&M Topping

73.00

5. Alcoholic Fruit Punch

64.40

Bundles with a High Vice Ratio

1. Deep-Fried Herbal Chicken

2. Organic Cake

3. Fiber Cookies

4. Ice Cream with Fruit Topping

5. Carrot Cake

\section{Perceived Virtue Score (100 = Virtue $)$}

34.60

35.85

30.92

34.82

30.92

\section{Study 1}

Source: Authors' own research.

\section{Experimental Design}

To test hypotheses 1 through 3b, we constructed a 2 (Thai vs. American participants) $\mathrm{x}$ 2 (vice-heavy vs. virtue-heavy bundle) ANOVA. To mimic the reality that consumers can encounter both types of vice-virtue combinations simultaneously at a grocery store, we manipulated the two types of vice-virtue combinations as a within-subject measure.

\section{Sample and Procedure}

Our sample for Study 1 consisted of 70 undergraduate students (35 Thai participants from Thailand, and 35 American participants from the United States) who participated in the study in exchange for extra course credits. The average age of participants was 21 years and about $60 \%$ of them were female. Both groups of participants were shown a list of five vice-heavy bundles and five virtue-heavy bundles that we obtained from the pretest. They were first asked to rate the likelihood of choosing each option for their own consumption on a 5-point scale ( $5=$ will definitely choose this food). Participants were instructed to assume no budgetary constraint so they should not evaluate each option based on perceived price.

Next, they were shown the same ten options again and were asked to select as many options as they like. Then, they completed the Analysis-Holism Scale provided by Choi et al. (2007). Afterwards, we assessed the perceived level of fit between the category and ingredient in each option fit together by employing a 5-point scale $11=$ they do not fit together, 5 = they fit very well together). They also reported their perception of taste and healthiness for each option on a similar scale used in the pretest. Finally, participants reported their familiarity with these ten options $(1=\mathrm{I}$ do not recognize the food at all, and $5=$ I regularly eat this food), and how health-conscious they are in the domain of food ( 1 = In general, I am very unlikely to select healthy food for my consumption, 5 = very likely). 
MMCKS Analyses and Results

The familiarity of food options and the level of health consciousness were used as covariates, but neither showed significant effects nor interaction effects with other predicting variables. Since the results do not change significantly with or without these covariates, for ease of exposition, we report the results of the analyses without these covariates in the models.

Perceived Fit between Vice and Virtue. We used the average score of perceived fit of the vice-heavy bundle and of the virtue-heavy bundle as the two repeated-measures dependent variables. To test our first Hypothesis, which states that consumers from Asian cultures will perceive greater fit between the ingredient and the category than consumers from Western cultures, we ran a 2 (Thai vs. American) x 2 (type of bundle) repeated-measures ANOVA. The analysis showed a significant main effect of culture $(F(1,62)=38.99, \mathrm{p}<.01)$, a significant main effect of bundle type $(F(1,62)=17.21, p$ $<.01)$, and a significant interaction effect $(F(1,62)=15.29, \mathrm{p}<.01)$. The results indicate that when evaluating both types of vice-virtue combinations, Thai participants (versus American participants) perceive a greater fit between vice and virtue components, and this difference in perceived fit among the two consumer groups is more pronounced among the vice-heavy options (Thai participants: $\mathrm{M}_{\text {vice-heavy }}=4.66, \mathrm{M}_{\text {vir-heavy }}=4.65$; American participants: $M_{\text {vice-heavy }}=3.19, M_{\text {virtue-heavy }} 3.91$ ). Thus, Hypothesis 1 is supported.

Perceived Healthiness. Similar to the previous analysis, we used the average score of healthiness for each type of bundle as dependent variables and ran a similar repeated-measures ANOVA. The main effect of culture is not significant $(p>.05)$ upon the participant's perception of the health value of the vice-virtue bundles, but the main effect of bundle type is significant $(F(1,62)=4.23, \mathrm{p}<.05)$. The interaction effect is also significant $(F(1,62)=5.07, \mathrm{p}<.05)$. Bonferroni pairwise comparisons revealed that American participants perceive that the virtue-heavy bundle to be healthier than the vice-heavy bundle $\left(\mathrm{M}_{\text {vice-heavy }}=2.88, \mathrm{M}_{\text {virtue-heavy }}=3.33, p<.01\right)$, supporting H2a. In comparison, Thai participants perceive both types of bundle as equally healthy ( $\mathrm{M}_{\text {vice- }}$ heavy $=3.15, \mathrm{M}_{\text {virtue-heavy }}=3.13, p>.05$ ) which confirms H2c.

Perceived Tastiness. A similar analysis was conducted on the average perceived tastiness score. No significant effects surfaced (all $p$ values $>.05$ ), so the results indicate that both Thai and American participants perceive that both bundle types are equally tasty (Thai participants: $\mathrm{M}_{\text {vice-heavy }}=3.62, \mathrm{M}_{\text {virtue-heavy }}=3.60$; American participants: $\mathrm{M}_{\text {vice- }}$ heavy $=3.56, M_{\text {virtue-heavy }}=3.20$ ). Therefore, these results do not provide support for $\mathrm{H} 2 \mathrm{~b}$, however they do confirm $\mathrm{H} 2 \mathrm{~d}$.

Next, to test our hypotheses regarding the preference for these two bundle types, we used two different measures: likelihood of choosing each option and the number of food options the participants selected for their own consumption.

Likelihood of Choosing Each Option. A similar ANOVA was conducted using the average likelihood to choose each bundle type as dependent variables. We found that the main effect of culture to be significant $(F(1,68)=3.99, p=.05)$, but the main effect of bundle type was not $(p>.05)$. However, the interaction effect was significant $(F(1,68)=$ 8.30, $p<.01$ ) with Bonferroni pairwise comparisons showing that Thai participants report similar buying likelihood across both types of bundle $\left(\mathrm{M}_{\text {vice-heavy }}=3.16, \mathrm{M}_{\text {virtue- }}\right.$ heavy $=3.00, p>.05$ ), whereas American participants report stronger likelihood to choose food options that have a higher virtue ratio $\left(\mathrm{M}_{\text {vice-heavy }}=3.30, \mathrm{M}_{\text {virtue-heavy }}=3.71, p<.01\right)$. This finding supports our H3a and H3b. 
Number of Foods Selected for Consumption. To provide more robust results for $\mathrm{H} 3 \mathrm{a}$ and $\mathrm{H} 3 \mathrm{~b}$, we also compared the number of vice-virtue bundles selected by each group. Consistent with the choice likelihood results, we found a significant interaction effect of culture and bundle type $(F(1,68)=10.34, p<.01)$. Bonferroni pairwise comparisons show that American participants select a greater number of virtue-heavy options than the other type $\left(\mathrm{M}_{\text {vice-heavy }}=1.40, \mathrm{M}_{\text {virtue-heavy }}=2.20, p<.01\right)$ and thus reconfirms H3a. Also consistent with our previous results, Thai participants selected approximately the same number of bundles across the two types $\left(\left(\mathrm{M}_{\text {vice-heavy }}=1.88\right.\right.$, $\mathrm{M}_{\text {virtue-heavy }}=1.65, p>.05$ ). This result reconfirms H3b.
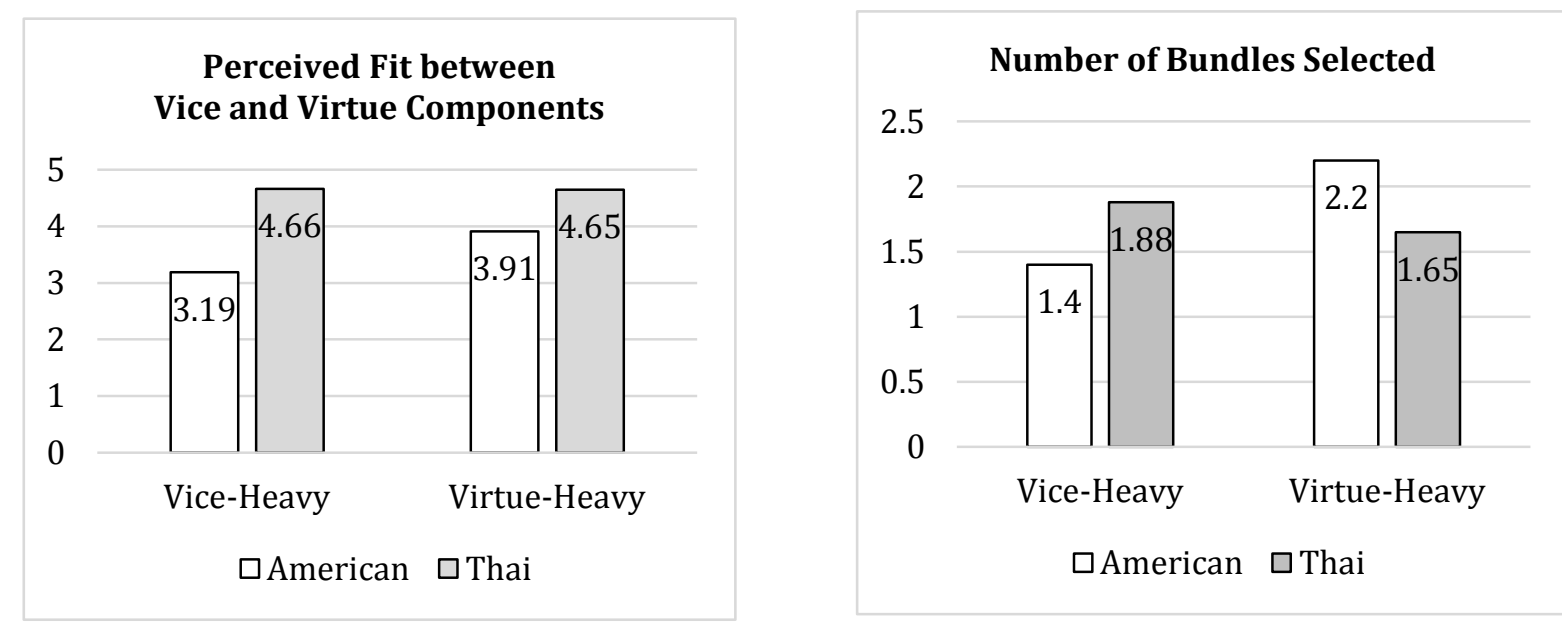

Figure 1. Results of study 1

Source: Authors' own research.

Holistic versus Analytic Processes. To identify whether the style of thinking contributed to the results, we ran a two-independent-sample $t$ test on the holistic thinking score. As expected, the analysis revealed that Thai participants engage more in holistic thinking style than American participants $\left(\mathrm{M}_{\text {Thai }}=5.14, \mathrm{M}_{\text {American }}=4.80, t(62)=\right.$ $2.80, p<.01)$.

Once we established that Asian participants in our study were more likely to deploy holistic thinking patterns, we sought to identify the underlying mechanism driving our participants to their particular bundle choices. As we hypothesized, the degree to which they perceived a fit between the components of the bundle should be driving their decisions. Therefore, we conducted a mediation analysis (Baron and Kenny, 1986) for the number of vice-heavy bundles and the number of virtue-heavy bundles. American culture was coded as 0 and Thai culture was coded as 1 . The coefficients and significant levels are reported in Figure 2.

Mediation Analysis for Virtue-Heavy Bundles. The first regression tested a direct path of the effect. Specifically, it confirmed that culture significantly impacts the number of virtue-heavy bundles selected by the participants. The second regression confirmed that culture significantly influenced the perceived fit between the components of the bundle. The third regression shows that when both culture and perceived fit are predicting variables in the model, they both significantly impact the number of virtueheavy bundles selected by participants. Then, we performed the Sobel test (1982) to statistically investigate the mediation effect. Results show that perceived fit is a significant mediator of the effect of culture on the number of virtue-heavy bundles selected by the participants $(z=2.97, p<.01)$. The direct effect of culture on the dependent variable is still significant, so it appears that this is a partial mediation. 
Mediation Analysis for Vice-Heavy Bundles. A similar procedure was conducted on the number of vice-heavy bundles selected by participants. However, the first regression shows that culture does not significantly impact this dependent variable $(\beta=$ $.23, p=.24)$, so no further regression was performed.

a) Direct Path

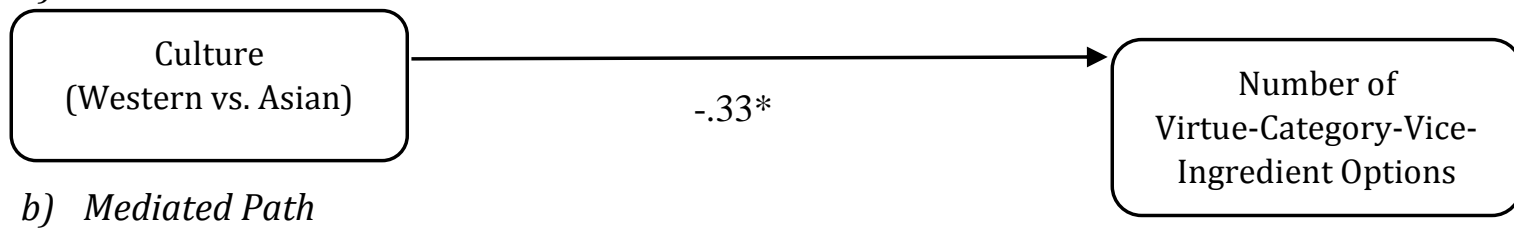

b) Mediated Path

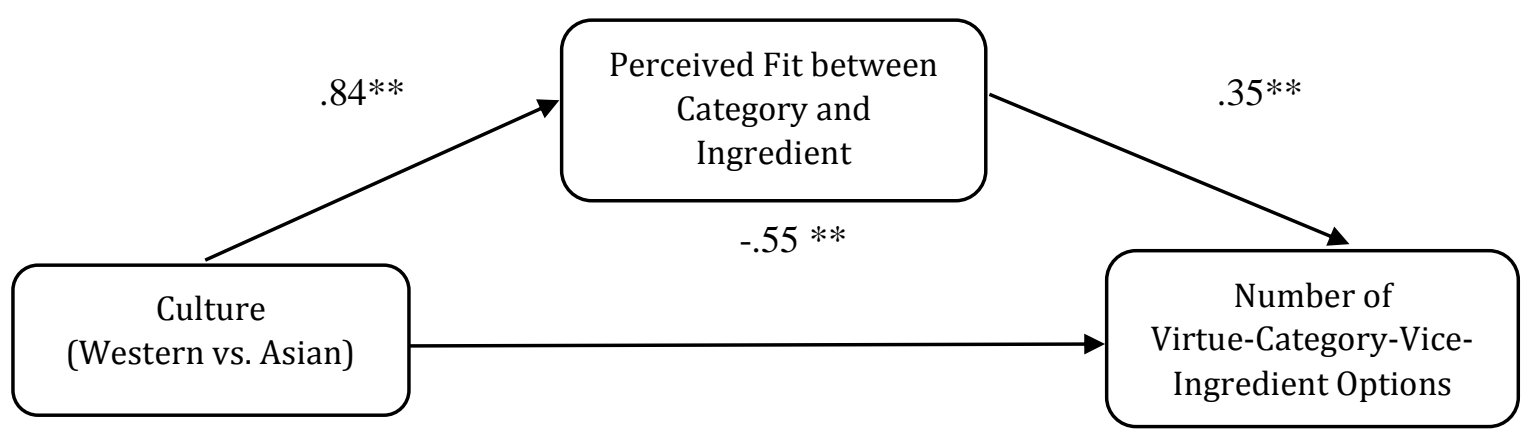

Figure 2. Mediation analysis

Source: Authors' own research.

Figure 2 shows the coefficients, and significant levels for the three regressions (*indicates that $p$ value $<.05$ and ${ }^{* *}$ indicates that $p$ value $<.01$ )

\section{Study 1 Discussion}

Study 1 provides three results important to our present argument. The first is that through the support of all but one Hypothesis (H2b), we demonstrate that Asian and Western participants perceive vice-virtue bundles in a markedly different manner. We argue that this difference is driven by the different criteria used by each group of participants when choosing between these bundles. Second, our results show that Western participants are more apt to focus on the components of a bundle and tend to prefer bundles with higher virtue content. Finally, Asian participants were less likely to exhibit a preference between bundles and expressed a greater degree of fit between the individual components in the bundles. We argue this finding is a result of the propensity of the individuals from Asian cultures to focus less on the individual components of the bundle and instead consider them in the context of their overall diet.

In conclusion, Study 1 demonstrates the cultural differences between Asian and Western participants' evaluation of vice-virtue bundles. However, we do not know to what extent these differences may remain when the participants receive information that may differ from their cultural predispositions. Therefore, in Study 2, we test the boundary condition of culture by activating the participants' regulatory focus; a prime that has been shown to override the influence of culture.

\section{Study 2}

\section{Experimental Design, Sample, and Procedure}

We constructed a 2x2x2 ANOVA featuring culture (Thai vs. American participants), food bundle (vice-heavy vs. virtue-heavy ratio), and regulatory focus (prevention-focused vs. 
promotion-focused goal) in order to assess the influence of regulatory focus primes upon the participants' propensity to choose vice-virtue bundles. The bundle type (viceor virtue-heavy) was a repeated-measures factor. One hundred and thirty five undergraduate students (75 Thais and 60 Americans) participated in this study in exchange for extra course credits. Average age was 21 years old and $52 \%$ of the participants were female.

To manipulate the participants' regulatory focus goals, we evenly split each culture into two groups. One group was asked to reflect upon their hope and aspirations prior to the study; whereas the other group was asked to reflect upon their current obligations (Leonardelli et al., 2007). Next, similar to Study 1, each participant was asked to report the likelihood that he or she would choose each of the ten vicevirtue bundles for their own consumption on a 5 -point scale ( $5=$ will definitely choose this food). To strengthen the regulatory focus manipulation, participants in the promotion-focused condition were asked to keep in mind "the goal to promote good health" while evaluating the food choice. Similarly, those in prevention-focused condition were asked to keep in mind "the goal to prevent sickness." Next, we presented the same ten options again. The participants were instructed to select as many bundles as they wished. The participants then completed the Analysis-Holism Scale, reported their familiarity with each food bundle and the degree of fit between the various components of the bundle using similar measures as in Study 1. Lastly, they completed a regulatory focus manipulation check adopted from Higgins and associates (2001).

\section{Analyses and results}

Analysis of the manipulation check showed that regulatory focus was successfully manipulated. Participants in the promotion-focused condition scored higher on promotion-focused items than prevention-focused items $(\mathrm{M}=3.94 \mathrm{vs.} 3.70, t(65)=3.50$, $p$ <.01). Likewise, participants in the prevention-focused condition scored higher on prevention-focused items than promotion-focused items $(\mathrm{M}=3.97$ vs. $3.78, t(66)=2.68$, $p<.01)$.

Holistic versus Analytic Thought Processes. To determine the boundary condition of culture, we ran a 2x2 ANOVA with culture (Thai vs. American participants) and regulatory focus (prevention-focused vs. promotion-focused goal) using the holistic process measure as a dependent variable. The results revealed that neither culture nor regulatory focus manipulation significantly affects holistic process $(F<1)$. Next, we ran a similar ANOVA using the analytic process measure as dependent variable. The analysis revealed an insignificant effect of culture $(F<1)$, but a significant effect of regulatory focus $(F(1,124)=5.31)$ showing that prevention-focused participants engage more in analytic thinking than promotion-focused participants $(\mathrm{M}=5.20$ vs. $4.22, t(124)=2.30$, $p=.02$ ). These results support Hypothesis 4, as they not only demonstrate the regulatory prime temporarily negates the participants' propensity to engage in particular thought patterns, but also that the prime was more effective than we had anticipated, as the participants subjected to the prevention prime were more likely to demonstrate characteristics consistent with the analytical thought processes.

Perceived fit between vice and virtue components. Next, to test Hypothesis 5, we conducted a $2 \times 2 \times 2$ ANOVA on the perceived fit score. The ANOVA contained culture (Thai vs. American participants), regulatory focus (prevention-focused vs. promotion- 
MMCKS focused goal) and food bundle type (high vice vs. high virtue ratio) as a repeated factor. The results of the analysis confirmed the Hypothesis 5. Specifically, they show a significant main effect of regulatory focus $(F(1,122)=52.29, p<.01)$ demonstrating that, for both types of bundles, promotion-focused participants report greater fit between vice and virtue components than the prevention-focused participants (M for high-viceratio options $=4.34$ vs. $3.58 ; \mathrm{M}$ for high-virtue-ratio options $=4.37$ vs. $3.73, p<.05$ respectively). However, the effect of culture was not completely extinguished as we also observed a significant main effect of culture $(F(1,124)=9.80, p<.01)$ indicating that Thai participants report greater fit between vice and virtue than American participants in both types of bundles ( $\mathrm{M}$ for vice-heavy options $=4.13$ vs. $3.67 ; \mathrm{M}$ for virtue-heavy options $=4.10$ vs. $3.99, p<.05$ respectively).

Likelihood of Choosing Each Option. A similar ANOVA was conducted on the likelihood of choosing each bundle. The main effect of culture is insignificant $(F(1,122)=.25, p=$ .62), but the main effects of bundle type and regulatory focus are significant $(F(1,122)=$ $10.23, p<.01$ and $F(1,122)=4.20, p<.01$ respectively). All interaction terms are not significant $(F<1)$. Bonferroni pairwise comparisons show that for both types of bundles, prevention-focused participants reported lower likelihood to choose either type of bundle than promotion-focused participants ( $\mathrm{M}$ for vice-heavy options $=3.08$ vs. $3.28, p$ $<.05$; $\mathrm{M}$ for virtue-heavy options $=2.79$ vs. 3.00, $p<.05$ ). Thus, Hypothesis 6 was supported. The significant main effect of bundle type suggests that vice-heavy options are more likely to be selected than the virtue-heavy options ( $\mathrm{M}=3.18$ vs. $2.89, p<.05)$ across both conditions.

Number of Bundles Selected for Consumption. Next, we conducted a similar ANOVA as the previous analysis, but changed the dependent variable to the number of bundles selected for consumption by each participant. Consistent with the previous results, only the main effect of regulatory focus and the main effect of bundle type are significant. Specifically, across both types of bundles, prevention-focused participants select fewer options than promotion-focused participants $(F(1,124)=7.38, p<.01$; M for vice-heavy bundles $=2.09$ vs. $2.28, p<.05 ; \mathrm{M}$ for virtue-heavy bundles $=1.51$ vs. $1.79, p<.05$ ). Therefore, the results again support Hypothesis 6 . The main effect of bundle type indicates that participants selected a greater number of vice-heavy options than the virtue-heavy options $(F(1,124)=52.94, p<.01 ; \mathrm{M}=2.19$ vs. 1.64$)$.

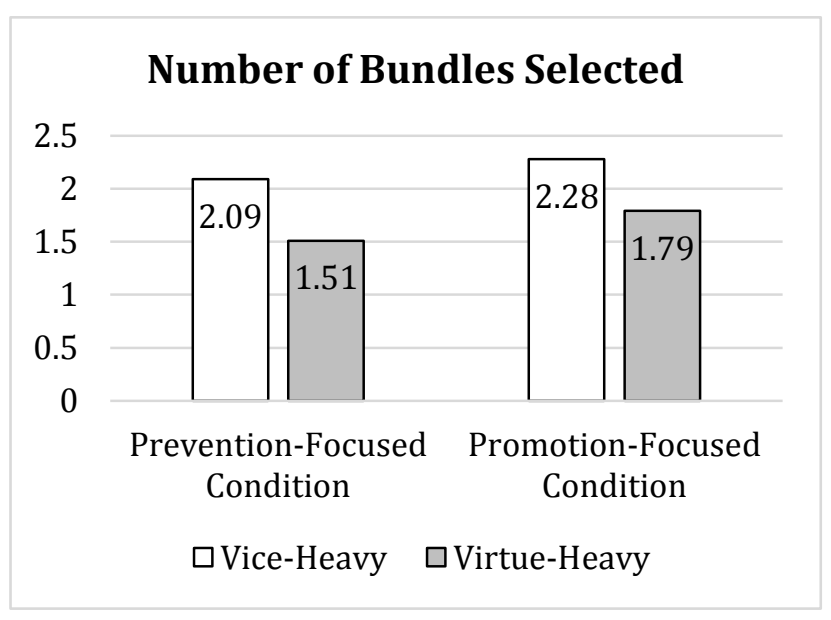

Figure 3. Result of study 2

Source: Authors' own research. 
Study 2 sought to determine the boundary conditions of culture's influence on the participants' perception of vice-virtue bundles. First, we established that a brief regulatory focus prime (health promotion or sickness prevention) can temporarily suspend the participants' typical thought patterns (holistic or analytical). Moreover, our results demonstrated that participants in the prevention condition more readily engaged in analytical thought processes.

Then, we illustrated the impact of a regulatory focus prime upon the participants' perceptions of the vice-virtue bundles. Specifically, our results show that participants in the promotion condition were more likely to choose vice-heavy bundles, thus supporting Hypothesis 5a. Participants in this condition were also more likely to find that the components of the vice-virtue bundles fit together.

Unexpectedly, the influence of culture observed in Study 1 reemerged in the assessment of fit. We observed a somewhat significant interaction effect $(p=.06)$ between culture and perceived fit of both bundle types. Moreover, this relationship was more pronounced in the promotion condition of the Thai participants. We interpret this as the promotion prime amplifying the Thai participants' inclination to perceive a greater fit between components, a dynamic observed in Study 1. In other words, the collective nature of Asian cultures' desire to maintain social harmony may be manifested (and amplified) in their perception of the bundles. Yet, when action is required of the participant, such as choosing specific vice-virtue bundles, the collective sentiment seems to lose relevance. Here the prevention prime gains primacy and overrides culture for both participants from Thailand and the U.S. So, while one's culture may impact the perception of a vice-virtue bundle, the regulatory focus prime overrides that influence when the participant is required to act on that perception.

Next, we discuss the implications of both studies.

\section{Conclusion}

Our research uncovers cultural differences in consumer evaluation of food with vice and virtue bundled together within a single choice. Consumers from Asian cultures evaluate both vice-heavy options and virtue-heavy options as equally favorable. In contrast, consumers from Western cultures show stronger preference for the virtue-heavy bundles; the proverbial "spoonful of sugar to make the medicine go down," rather than the healthy indulgence of the vice-heavy bundle. Moreover, our results are consistent across two dependent variables: the likelihood of choosing the food and the number of options selected for their consumption, adding to the strength of these findings.

Process measures help shed light on possible mechanisms underlying the effect. First, as expected, consumers from Asian cultures engage in a more holistic thinking style than Westerners. Second, as predicted, consumers from Asian cultures perceive a greater fit of components than Westerners. These two measures together support our assumption that holistic thinking helps Asians draw relationships between ingredients beyond the vice and virtue aspects of food, whereas the analytic thinking prevalent among Westerners may lead them to a more narrow view of the relationship between the components. The results suggest that these participants in the latter category focus only on the vice-virtue differences between the component types (vice or virtue) and thus perceive the bundle components to be incongruent.

Other possible explanations of our findings may be that i) Asians may be more familiar with a wider range of food options than Westerners and that ii) Westerners could be more health-conscious than Asians given that obesity has become a public 
concern in the U.S. However, these measures were used as covariates in the analysis and the results show that they do not affect consumer evaluation of the food nor do they interact with any predicting variables. Thus, we can rule out these alternative explanations.

One interesting result from the studies show that consumers from both cultures perceive both bundle types as equally tasty, yet they differ in their preference of bundle type. This means that although consumers in Western cultures find poor fit between the components of the bundle, it does not significantly impact the perceived taste of either bundle type. Our mediation provided additional insight into this observation. It appears that the effect of culture on consumer preference for the two types of bundles being driven by different mechanisms. First, when evaluating a virtue-heavy bundle, the perceived fit between vice and virtue components mediates the effect of culture on preference. However, when evaluating a vice-heavy bundle, the perceived fit does not mediate the effect of culture. This indicates that a vice-heavy bundle may trigger consumers to focus less on the ingredient within the food, but more on other factors such as perceived healthiness, or the guilt of consuming a vice food category. Such a finding is at odds with previous research on vice and virtue ingredients (Chernev and Gal, 2010), which would predict that participants will average benefits of virtue and vice. If that were the case in this study, there would be no difference between the two conditions. Our findings indicate a more complicated calculus may be at play, in which the consumer may construct a balance sheet of vice and virtue ingredients.

The second study not only demonstrated that typical thought patterns may be temporarily overcome through the priming of an individual's regulatory focus, it also illustrated the power of culture when assessing fit. Specifically, Thai participants were more likely to conceive the components of both types of bundles to fit than their American counterparts. We also identified the influence of the promotion condition on the choice of bundle types.

\section{Contributions, implications, and limitations}

This research establishes a novel linkage between culture, style of thinking, and food categorization literature. We add to consumer behavior literature by reporting cultural differences in the context of vice-virtue food evaluation, and this research is among the first attempts to explore a vice-virtue combination within a single food choice.

In consumer behavior literature, healthy living and food consumption have become more important topics of inquiry in recent years (Oakes and Slotterback, 2005, Seiders and Petty, 2004, Wansink and Huckabee, 2005). Prior research on vice-virtue consumption has focused on how consumers respond to vice and virtue food choices (Chernev and Gal, 2010, Mishra and Mishra, 2011, Read et al., 1999, Wertenbroch, 1998) but the vice and virtue options tend to be two separate options (e.g. hamburger and salad). This research is among the first attempts to understand how consumers evaluate a vice-virtue bundle within a single choice. With an increasing number of such products in the market, how these products are perceived by consumers should be of interest to marketers.

The findings suggest that Western consumers have a strong preference for virtue-heavy bundles. Consistent with Milkman (2013), the "spoonful of sugar" helps consumers reach their health goals by consuming virtuous foods that may be slightly tastier than most "health foods." However, such judgments are not in play for Thai consumers. Instead, we show that consumers in Asian cultures find both types of 
bundle equally attractive. Future research can investigate whether these consumers are later led to believe that after consuming a vice-heavy dish, they can reward themselves with another vice option. If that is the case, the vice-heavy bundle could, for example, lead to an over intake of calories.

We show that consumers prefer congruent ingredients in virtue-heavy bundles and marketers may be wise to avoid combinations that may appear too strange when considering healthy indulgences. However, our results also indicate that vice-heavy bundles do not suffer from the same constraints and that consumers may be much more receptive to interesting combinations of indulgent foods. Perhaps this line of thinking is driving beverage and snack companies to introduce products such as bacon-flavored soda and Dorito taco-shells.

Our findings provide theoretical contributions to cross-cultural psychology and consumer behavior literature as well. In cross-cultural psychology, the holistic-analytic framework has often been tested using visual perception (Abel and Hsu, 1949, Chua et al., 2005, Masuda and Nisbett, 2000, Nisbett and Miyamoto, 2005, Nisbett et al., 2001, Kitayama et al., 2003). We extend this literature by providing empirical evidence of how a holistic-analytic framework could impact food perception even when a visual stimulus is not presented. This suggests that such stimuli may not be required to analyze holistic vs. analytic processing. Moreover, future research may seek to understand the differences when visual cues are present. For example, one may examine if providing pictures of both bundle types may impact the perception between the fit of the components in the bundle.

When we consider these results within the holistic/analytical framework, it would seem that the degree of fit between ingredients in virtue-heavy bundles matters because there may be other motivations for consuming the food beyond instant gratification, such as improving one's health. Any ingredient that would detract from the health goal would draw the attention of the analytical thinker. For vice-heavy bundles, fit exerts less influence. Here, incongruent ingredients may lessen guilt, or provide them with a "license" to indulge. For holistic thinkers here, the bundle represents the junk food element of their diet, making the composition of the bundles less relevant.

Furthermore, an understanding of the preferences of consumers from different cultures regarding vice-virtue bundles can help shed light on how they will respond to vice-virtue combinations in other products and services. Our findings are in line with the previous studies that have demonstrated the effects of bundling want and should behaviors (Liu et al., 2015, Milkman et al., 2013). Future research may wish to explore the cross-cultural perceptions of other bundling strategies. Possible combinations include learning and game play in education and other perceived consumer tradeoffs such as expensive vs. inexpensive, long vs. short term, environmental benefit vs. harm, and price vs. responsible manufacturing (Norum and Ha-Brookshire, 2011). Moreover, if the same perceptions hold true for task oriented actions, these findings could also have motivation implications for employees. Future research may wish to assess the differing perceptions of Thai and American employees when presented with a small reward embedded within a dreaded task.

Regarding managerial implications, previous research has highlighted the ability of vice-virtue bundles to improve brand attitudes and increase customer loyalty, as well as the number of repeat customers (Liu et al., 2015, Wansink, 2012). Our study echoes this earlier work, but also provides insight into the perception of these bundles between different cultures. These findings may help food and beverage manufacturers identify 
appropriate types of vice-virtue combinations for their target markets. Specifically, in Western countries, consumers are receptive to a guilty pleasure in their health food, must not deviate too far from the original conception of the dish. In contrast, where holistic thinking is a more common, such as in Asian countries, food and beverage manufacturers may wish to offer both types of combinations.

Our results also show that participants from both cultures found the bundles to be equally tasty. This result may be especially useful in targeting consumers that fall into the "Lifestyles of Health and Sustainability" segment (LOHAS). These consumers value environmental issues and healthy lifestyles and the Natural Marketing Institute estimates that this segment will spend $\$ 290$ billion annually (Nelson, 2012). Our findings indicate that both Western and Asian consumers seek virtuous food that contains a little vice, so that they can achieve their health goals in a more palatable manner.

Moreover, the findings show that participants in the promotion-focused condition responded more positively towards the bundles. Prior research has shown that regulatory focus can be used as a message framing strategy (Lee and Aaker, 2004, Levin et al., 1998, Rothman and Salovey, 1997). This result may suggest that firms can use promotion-focused message in their advertising campaigns and the effectiveness of the messages may persist across cultures.

This research could not be completed without any limitations. First, our research participants were college students. Generalizing the study results to other groups of consumers should be made with caution, because relative to general consumers, students have lower income, are younger and thus relatively healthier, and are less experienced in balancing between conflicting goals in life. Second, although the results of several measures are consistent with our hypotheses, the mechanism driving the preference for vice-heavy bundles remains unclear. Moreover, we did not consider the participants' perceptions of the bundles quality or desirability.

In conclusion, to the extent of the population studied, our study demonstrates that a majority of consumers in both the East and West either desire, or see no difference, when adding a spoonful of sugar to their medicine. Moreover, those consumers who fall into the promotion condition are more amenable to the bundling of vice and virtue ingredients into a single item. We suggest that academicians and managers continue to further our understanding of these phenomena, as these vicevirtue bundles are unlikely to disappear from the retailers' shelves anytime soon.

\section{Acknowledgements}

The authors thank Dr.Theeranuch Pusaksrikit, Dr.Panitharn Juntongjin, and Dr. Pornsit Jiraporn for assisting with data collection. We thank Thammasat Business School for providing funding for this research.

\section{References}

Abel, T. M. and Hsu, F. L. (1949), "Some aspects of personality of Chinese as revealed by the Rorschach Test", Rorschach research exchange and journal of projective techniques, Vol. 13, No.3, pp. 285-301.

Baron, R. M. and Kenny, D. A. (1986), "The moderator-mediator variable distinction in social psychological research: conceptual, strategic, and statistical considerations", Journal of personality and social psychology, Vol. 51, No.6, pp. 1173. 
Cesario, J., Grant, H. and Higgins, E. T. (2004), "Regulatory fit and persuasion: transfer from" feeling right."', Journal of personality and social psychology, Vol. 86, No. 3, pp. 388.

Chandon, P. and Wansink, B. (2007), "The biasing health halos of fast-food restaurant health claims: lower calorie estimates and higher side-dish consumption intentions", Journal of Consumer Research, Vol. 34, No. 3, pp. 301-314.

Chernev, A. and Gal, D. (2010), "Categorization effects in value judgments: averaging bias in evaluating combinations of vices and virtues", Journal of Marketing Research, Vol. 47, No. 4, pp. 738-747.

Chiu, L.-H. (1972), "A cross-cultural comparison of cognitive styles in Chinese and American children", International journal of psychology, Vol. 7, No. 4, pp. 235242.

Choi, I., Koo, M. and Choi, J. A. (2007), "Individual differences in analytic versus holistic thinking", Personality and Social Psychology Bulletin, Vol. 33, No. 5, pp. 691-705.

Chua, H. F., Leu, J. and Nisbett, R. E. (2005), "Culture and diverging views of social events", Personality and Social Psychology Bulletin, Vol. 31, No. 7, pp. 925-934.

Crowe, E. and Higgins, E. T. (1997), "Regulatory focus and strategic inclinations: promotion and prevention in decision-making", Organizational behavior and human decision processes, Vol. 69, No. 2, pp. 117-132.

Dholakia, U. M., Gopinath, M., Bagozzi, R. P. and Nataraajan, R. (2006), "The role of regulatory focus in the experience and self-control of desire for temptations", Journal of Consumer Psychology, Vol. 16, No. 2, pp. 163-175.

Florack, A., Palcu, J. and Friese, M. (2013), "The moderating role of regulatory focus on the social modeling of food intake", Appetite, Vol. 69, No. 1, pp. 114-122.

Higgins, E. T. (1997), "Beyond pleasure and pain", American Psychologist, Vol. 52, No. 12, pp. 1280.

Higgins, E. T. (1998), "Promotion and prevention: regulatory focus as a motivational principle", in Zanna, M.P. (ed.) Advances in experimental social psychology, pp. 146 Academic Press, San Diego, CA.

Higgins, E. T. (2002), "How self-regulation creates distinct values: the case of promotion and prevention decision making", Journal of Consumer Psychology, Vol. 12, No. 3, pp. 177-191.

Higgins, E. T. (2005), "Value from regulatory fit", Current Directions in Psychological Science, Vol. 14, No. 4, pp. 209-213.

Higgins, E. T., Friedman, R. S., Harlow, R. E., Idson, L. C., Ayduk, O. N. and Taylor, A. (2001), "Achievement orientations from subjective histories of success: promotion pride versus prevention pride", European Journal of Social Psychology, Vol. 31, No. 1, pp. 3-23.

Hunt, R. R. and Einstein, G. O. (1981), "Relational and item-specific information in memory", Journal of Verbal Learning and Verbal Behavior, Vol. 20, No. 5, pp. 497514.

Istudor, N. and Pelau, C. (2011), "Clusters of consumer behavior for food and near-food products in Romania", Management \& Marketing, Vol. 6, No. 4, pp. 529.

Kitayama, S., Duffy, S., Kawamura, T. and Larsen, J. T. (2003), "Perceiving an object and its context in different cultures: a cultural look at new look", Psychological Science, Vol. 14, No. 3, pp. 201-206.

Kristensen, D. B., Askegaard, S. and Jeppesen, L. H. (2013), "'If it makes you feel good it must be right': embodiment strategies for healthy eating and risk management", Journal of Consumer Behaviour, Vol. 12, No. 4, pp. 243-252. 
Lee, A. Y. and Aaker, J. L. (2004), "Bringing the frame into focus: the influence of regulatory fit on processing fluency and persuasion", Journal of Personality and Social Psychology, Vol. 86, No. 2, pp. 205.

Leikas, S., Lindeman, M., Roininen, K. and Lähteenmäki, L. (2006), "Regulatory focus and food risk perceptions", Appetite, Vol. 47, No. 2, pp. 269.

Leonardelli, G. J., Lakin, J. L. and Arkin, R. M. (2007), "A regulatory focus model of selfevaluation", Journal of Experimental Social Psychology, Vol. 43, No. 6, pp. 10021009.

Levin, I. P., Schneider, S. L. and Gaeth, G. J. (1998), "All frames are not created equal: a typology and critical analysis of framing effects", Organizational behavior and human decision processes, Vol. 76, No. 2, pp. 149-188.

Liberman, N., Idson, L. C., Camacho, C. J. and Higgins, E. T. (1999), "Promotion and prevention choices between stability and change", Journal of Personality and Social Psychology, Vol. 77, No. 6, pp. 1135.

Liu, P. J., Haws, K. L., Lamberton, C., Campbell, T. H. and Fitzsimons, G. J. (2015), "Vicevirtue bundles", Management Science, Vol. 61, No. 1, pp. 204-228.

Masuda, T. and Nisbett, R. (2000), "Attending holistically vs. analytically: comparing the context sensitivity of Americans and Japanese", International Journal of Psychology, Vol. 35,No. 3-4, pp. 258-258.

McCarty, J. A., Horn, M. I., Szenasy, M. K. and Feintuch, J. (2007), "An exploratory study of consumer style: country differences and international segments", Journal of Consumer Behaviour, Vol. 6, No. 1, pp. 48-59.

Milkman, K. L., Minson, J. A. and Volpp, K. G. (2013), "Holding the Hunger Games hostage at the gym: an evaluation of temptation bundling", Management Science, Vol. 60, No. 2, pp. 283-299.

Mishra, A. and Mishra, H. (2011), "The influence of price discount versus bonus pack on the preference for virtue and vice foods", Journal of Marketing Research, Vol. 48, No. 1, pp. 196-206.

Monga, A. B. and John, D. R. (2007), "Cultural differences in brand extension evaluation: the influence of analytic versus holistic thinking", Journal of Consumer Research, Vol. 33, No. 4, pp. 529-536.

Nelson, T. N. (2012), 'The transformational consumer: the $\$ 300$ billion-plus opportunity most entrepreneurs have never heard of', Forbes, 2015. Available at: http://www.forbes.com/sites/taranelson/2012/07/09/the-transformationalconsumer-the-30-billion-plus-opportunity-most-entrepreneurs-have-neverheard-of/ (Accessed August 21, 2015).

Nisbett, R. E. and Miyamoto, Y. (2005), "The influence of culture: holistic versus analytic perception", Trends in cognitive sciences, Vol. 9, No. 10, pp. 467-473.

Nisbett, R. E., Peng, K., Choi, I. and Norenzayan, A. (2001), "Culture and systems of thought: holistic versus analytic cognition", Psychological review, Vol. 108, No. 2, pp. 291.

Norum, P. S. and Ha-Brookshire, J. E. (2011), "Consumer trade-off analysis and market share estimation for selected socially responsible product attributes for cotton apparel", Clothing and Textiles Research Journal, Vol. 29, No. 4, pp. 348-362.

Oakes, M. E. and Slotterback, C. S. (2005), "Too good to be true: dose insensitivity and stereotypical thinking of foods' capacity to promote weight gain", Food Quality and Preference, Vol. 16, No. 8, pp. 675-681.

Pfattheicher, S. and Sassenrath, C. (2014), "A regulatory focus perspective on eating Lee, A. Y. and Aaker, J. L. (2004), "Bringing the frame into focus: the influence of 
regulatory fit on processing fluency and persuasion", Journal of Personality and Social Psychology, Vol. 86, No. 2, pp. 205.

Leikas, S., Lindeman, M., Roininen, K. and Lähteenmäki, L. (2006), "Regulatory focus and behavior: how prevention and promotion focus relates to emotional, external, and restrained eating", Frontiers in Psychology, 5.

Pula, K., Parks, C. D. and Ross, C. F. (2014), "Regulatory focus and food choice motives. prevention orientation associated with mood, convenience, and familiarity", Appetite, Vol. 78, pp. 15-22.

Raghunathan, R., Naylor, R. W. and Hoyer, W. D. (2006), "The unhealthy = tasty intuition and its effects on taste inferences, enjoyment, and choice of food products", Journal of Marketing, Vol. 70, No. 4, pp. 170-184.

Read, D., Loewenstein, G. and Kalyanaraman, S. (1999), "Mixing virtue and vice", Journal of Behavioral Decision Making, Vol. 110, No. 3, pp. 257-273.

Reid, M., Li, E., Bruwer, J. and Grunert, K. (2001), "Food-related lifestyles in a crosscultural context: comparing Australia with Singapore, Britain, France and Denmark", Journal of Food Products Marketing, Vol. 7, No. 4, pp. 57-75.

Rothman, A. J. and Salovey, P. (1997), "Shaping perceptions to motivate healthy behavior: the role of message framing", Psychological Bulletin, Vol. 121, No. 1, pp. 3.

Rozin, P., Ashmore, M. and Markwith, M. (1996), "Lay American conceptions of nutrition: dose insensitivity, categorical thinking, contagion, and the monotonic mind", Health Psychology, Vol. 15, No. 6, pp. 438.

Safer, D. A. and Higgins, E. T. 2001. How do personal concerns influence preferences? The case of promotion and prevention concerns. Department of Psychology, Columbia University.

Scholer, A. A. and Higgins, E. T. (2012), "Too much of a good thing? Trade-offs in promotion and prevention focus", in Ryan, R.M. (ed.) The Oxford handbook of human motivation, pp. Oxford University Press, New York, NY.

Schuldt, J. P., Muller, D. and Schwarz, N. (2012), "The "fair trade" effect health halos from social ethics claims", Social Psychological and Personality Science, Vol. 3, No. 5, pp. 581-589.

Seiders, K. and Petty, R. D. (2004), "Obesity and the role of food marketing: a policy analysis of issues and remedies", Journal of Public Policy and Marketing, Vol. 23, No. 2, pp. 153-169.

Sengupta, J. and Zhou, R. (2007), "Understanding impulsive eaters' choice behaviors: the motivational influences of regulatory focus", Journal of Marketing Research, Vol. 44, No. 2, pp. 297-308.

Sobel, M. E. (1982), "Asymptotic confidence intervals for indirect effects in structural equation models", Sociological Methodology, Vol. 13, pp. 290-312.

Van Kleef, E., van Trijp, H. C. and Luning, P. (2005), "Functional foods: health claim-food product compatibility and the impact of health claim framing on consumer evaluation", Appetite, Vol. 44, No. 3, pp. 299-308.

Wansink, B. (2012), "Package size, portion size, serving size... market size: The unconventional case for half-size servings", Marketing Science, Vol. 31, pp. 1-54.

Wansink, B. and Huckabee, M. (2005), "De-marketing obesity", California Management Review, Vol. 47, No. 4, pp. 2.

Wertenbroch, K. (1998), "Consumption self-control by rationing purchase quantities of virtue and vice", Marketing Science, Vol. 17, No. 4, pp. 317-337. 
MMCKS Lee, A. Y. and Aaker, J. L. (2004), "Bringing the frame into focus: the influence of regulatory fit on processing fluency and persuasion", Journal of Personality and Social Psychology, Vol. 86, No. 2, pp. 205.

Leikas, S., Lindeman, M., Roininen, K. and Lähteenmäki, L. (2006), "Regulatory focus and Zhang, Y. and Mittal, V. (2007), "The attractiveness of enriched and impoverished options: culture, self-construal, and regulatory focus", Personality and Social Psychology Bulletin.

Zhou, B., Stamler, J., Dennis, B., Moag-Stahlberg, A., Okuda, N., Robertson, C., Zhao, L., Chan, Q. and Elliott, P. (2003), "Nutrient intakes of middle-aged men and women in China, Japan, United Kingdom, and United States in the late 1990s: the INTERMAP study", Journal of Human Hypertension, Vol. 17, No. 9, pp. 623-630.

Zhu, R. and Meyers-Levy, J. (2007), "Exploring the cognitive mechanism that underlies regulatory focus effects", Journal of Consumer Research, Vol. 34, No. 1, pp. 89-96. 